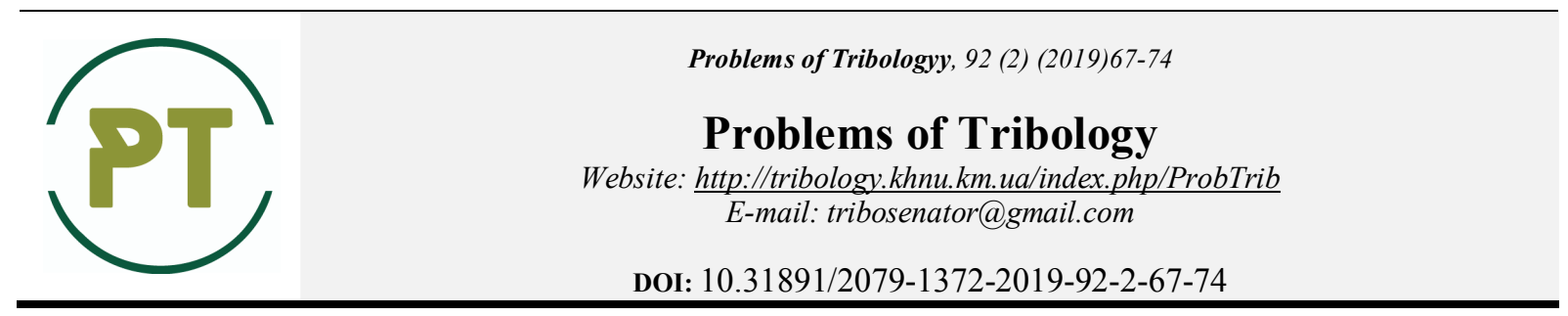

\title{
Modern studies of tribological bearing systems: a review
}

\author{
O. Dykha $^{1 *}$, V. Dytynyuk ${ }^{1}$, S. Posonsky ${ }^{1}$, L. Zelenska ${ }^{2}$ \\ ${ }^{1}$ Khmelnitskyi National University, Ukraine \\ ${ }^{2}$ Khmelnytskyi Polytechnic College by Lviv Polytechnic National,Ukraine \\ *E-mail:tribosenator@gmail.com
}

\begin{abstract}
Sliding bearings are one of the important friction points of modern machines, ensuring their long-term operation. Sliding supports determine the accuracy of the executive movements of the working parts of the machines. Creating and researching reliable and accurate sliding bearings is an important engineering issue. This review presents the results of studies of bearings, published in recent years in specialized scientific journals. The issues of creating efficient structural bearing assemblies, including through the use of new hybrid materials and structures, are considered. Much attention is paid to the problem of bearing wear and reducing the coefficient of friction. Separately considered issues of computer modeling of working conditions and design of structures. Considered modern approaches to the calculated evaluation of bearings, the solution of contact problems. This review allows scientists and engineers to do the right task setting when planning further research on bearing tribo systems..
\end{abstract}

Key words: sliding journal bearing, wear, friction, contact pressure, tests, materials.

Bearings are technical devices that are part of the supports of rotating axles and shafts. They take radial and axial loads applied to the shaft or axis and transfer them to the frame, housing or other parts of the structure. At the same time, they should also keep the shaft in space, provide rotation, swing or linear movement with minimal energy loss. The quality of bearings, efficiency and durability of the machine largely depend on the quality of bearings. This review presents the results of studies of bearings, published in the world specialized scientific journals over the past 3 years.

The article [1] employs an adaptive wear modeling method to study the wear progress in radial sliding bearings contacting with a rotary shaft. Mixed Lagrangian-Eulerian formulation has been used to simulate the contact condition between the bearing and the shaft, and the local wear evolution is modeled using the Archard equation. In the developed wear processor algorithm, not only remeshing is performed on the contact elements, but also is executed for their proximity elements. In this way the wear simulation becomes independent of the size of the contact elements. Validation was done for a laminated polymeric composite bearing. The composite has been modeled as a linear orthotropic material. The wear coefficients were obtained from flat-on-flat experiments and were applied as pressure and velocity dependent parameters in the wear processor. Finally, the effect of the clearance on the wear of the radial bearings has been studied numerically. The simulations also demonstrate how the contact pressure evolves during the wear process, and how the clearance influences this evolution.

The study [2] aims to predict the wear in journal bearings during steady-state operation in the mixedlubrication regime starting with a critical assessment of commonly used wear laws. A novel numerical method is introduced that calculates journal bearing wear on macroscopic and asperity contact scale. For validation of the numerical method, the friction and wear behavior was studied on a special test-rig for journal bearings. Both experimental and numerical results show an initial period of high friction and wear. After the first minutes of operation reduced friction can be observed. The simulations clarify, that this is caused by bearing wear on asperity roughness scale. By considering the reduced asperity interaction due to wearing-in in the calculation of contact conditions a higher accuracy of wear prediction is achieved.

Leaded tin bronze alloys are widely used in heavy machinery bearings operating in boundary and mixed lubrication regions due to the excellent dry lubrication properties of lead. However, restrictions on the use of lead have created an increasing demand for lead-free or low-lead bearing materials. In the study [3], suitability of 
a novel bismuth bronze bimetal material for possible substitution of leaded tin bronze was studied with a special thrust bearing test device, which simulates the contact conditions in the main thrust bearing of mineral crushers. The oil-lubricated test bearings have a flat-on-flat type contact with oil grooves and a constant eccentric motion against a case hardened steel counter plate under a periodically increased axial pressure. The test was continued until a sudden rise in friction, which indicates bearing failure and risk of an imminent seizure. The bismuth bronze showed a load capacity of the same level with the reference material, continuously cast CuSn $10 \mathrm{~Pb} 10$. Characterization by electron microscopy showed that the dry-lubricating bismuth precipitations had a fine grain size and an even distribution, which explains the good load carrying capacity. It was concluded that the bismuth bronze has potential for substituting the leaded tin bronzes in the studied operating conditions.

The paper [4] investigates the performance of a ferrofluid based hydrodynamic journal bearing system considering different combination of shaft and bearing materials. An investigation was first carried out for the material combination of ferrous and non-ferrous for shaft and bearing respectively, in the presence of a ferrofluid. Thereafter, analysis was conducted for the ferrous with ferrous material combination. Film pressure and temperature rise were measured for varying speeds and loads. It was noticed that the film pressure generation failed owing to the attraction in the case of ferrous and ferrous material combination for the bearing and magnetic shaft. Further, the temperature rise was found to be nearly double in the case of ferrous with ferrous, in comparison with ferrous with non-ferrous material combination under certain operating conditions. Besides, for moderate loads and speeds, the film pressure in case of ferrofluid lubrication for ferrous and nonferrous combination increased considerably as compared to that of the conventional lubricant based journal bearing systems. Moreover, the temperature rise was much smaller for ferrofluid lubricants as compared to conventional lubricants, thus, making the system cooler while running. Finally, wear analysis was carried out on the ferrofluid based journal bearing system by microscopic observation of the bearing surfaces, weight loss and DLS of fluid. This study indicated that the ferrous and non-ferrous material combination could probably turn out to be a suitable option for the ferrofluid based journal bearing system.

Hydrodynamic sliding bearings are designed to operate under fully flooded conditions to enable adequate film formation. In actual operating conditions, journal bearings could operate in a mixed or even boundary lubrication regime, for example, during the start-up/shut-down period. To prevent bearing destruction, a specific surface texture can be created on the sliding zones. One of the roles of surface irregularities is to maintain a certain amount of oil in the case of its shortage.

The aim of the study [5] was to identify the characteristic parameters, such as the sliding velocity, Hersey number, and friction torque or friction coefficient, when the transition of lubrication regimes occurs for different journal bearing types. The study demonstrates the results achieved in experimental investigations conducted on journal bearings, with the oil pockets on the journal surface mating with the smooth bearing and with the texture on the bearing surface co-acting with a standard smooth journal. The obtained results were also compared with the tested effects of the classical, smoothly finished journal bearing. It was found that, during shut-down, the textured journal bearings remained in hydrodynamic lubrication for longer and moved to mixed lubrication at lower speeds compared to the smooth journal bearing.

Oil contamination resulting from externally ingested particles is one of the major causes of journal bearing failure in industrial machinery. The present study has been carried out to assess the case of externally ingested particle contaminants in a journal bearing lubrication using acoustic emission (AE) and vibration monitoring techniques. Besides quantitative evaluation, the features of $\mathrm{AE}$ and vibration spectra have been classified and key parameters for condition monitoring deduced. Furthermore, cases involving different particles sizes and concentrations have been exhaustively examined and illustrated; and the capability of these two methods described in terms of detectability.

This paper [7] investigates the impact of heat transfer between leading and trailing pad free surfaces and the space between pad regions of high-speed tilting-pad journal bearings. General influence on pad metal temperature distributions as well as magnitudes of resulting heat convection coefficients are theoretically analyzed and validated with test data for sliding speeds up to $94 \mathrm{~m} / \mathrm{s}$ and specific loads up to $3.0 \mathrm{MPa}$. Results indicate significant impact of trailing pad free surface heat transfer on maximum pad metal temperatures as well as potential for optimization based on the general flow pattern. Moreover, limitations, extensions, and improvements of the presented study are comprehensively discussed.

In [8] a transient Mixed Lubrication-Wear coupling model (MLW coupling model) is developed to investigate the mixed lubrication and wear performances of journal bearings, and a wear experiment for journal bearing is performed to support the validity of the developed numerical model. In the coupling numerical model, the transient interaction between the behaviour of mixed lubrication and wear is considered by incorporating the wear depth distribution, which is determined by the developed friction fatigue wear model, into the film gap equation. The evolutions of the worn surface profile, wear rate, fluid pressure and asperity contact pressure over operating time are calculated by the developed numerical model. The simulated results demonstrate that the transient wear process affects the distribution trend of lubrication performances significantly, and a worn surface profile may exist that provides an optimal tribology performance of journal bearings. The simulated results also demonstrate that there are two wear stages, identified by initial and steady wear stage, of journal bearings under mixed lubrication condition. Furthermore, the effects of the input parameters, including the radius clearance $(C)$, 
surface roughness $(\sigma)$, asperity curvature radius $(\beta)$ and boundary friction coefficient $\left(\mu_{c}\right)$, on the predicted mixed lubrication and wear performance are evaluated.

Currently used turbulent lubrication model [9] that considers the effects of surface roughness can only handle the isotropic rough surfaces and cannot handle the rough surfaces with directional properties. In this paper, based on the stochastic method and the Ng-Pan turbulent model, the stochastic turbulent lubrication models of one-dimensional longitudinal rough surface, one-dimensional transverse rough surface and isotropic rough surface are derived. The turbulent lubrication performance of a journal bearing with isotropic rough surface is calculated by the stochastic turbulent lubrication model. The results are in good agreement with the corresponding experimental data. Moreover, the proposed stochastic turbulent lubrication models are also suitable for parts of friction pairs such as journal bearing and thrust bearing.

The dynamic contact behavior of hydrodynamic journal bearings during start-up is investigated [10]. The hydrodynamic oil force and asperity contact force are obtained by solving the mixed lubrication model. The motion of the journal center, the contact time, and the lift-off speed of the bearing are determined. The effects of the relative clearance and acceleration time are discussed. The result shows that the hydrodynamic oil force increases sharply during the early stage of the start-up process, leading to a sharp decrease in the contact force. An increase in the relative clearance of the bearing generates a decrease in both the contact force and the contact time. Also, a high start-up acceleration leads to a sharp decrease in the contact force.

This paper discusses the further development of an analytical model to calculate the minimum film thickness and the transition speed in journal bearings with consideration of bearing deformations. The focus of the development was on generalising an existing model to include any relative eccentricities and width/diameter ratios. Furthermore, the influence of different bearing types and the layer structure of plain bearings on the deformation are taken into account. Using two white metal journal bearings as examples, the results of the new approach are discussed and compared with previous analytical models and full numerical calculations.

Hydrostatic assistance is a commonly used method to improve limited load carrying ability of tiltingpad thrust bearings during transient states of operation of vertical shaft hydro-generators [12]. Despite of special hydraulic equipment (as pumps, valves, etc.), it also requires manufacturing of special recesses/pockets at pad sliding surfaces, into which oil is injected under high pressure. It allows to lift the rotor before start-up of the machine and form a hydrostatic film between pads and collar. There is a quite wide variety of geometry of recesses (shape, depth, and size) met in practical large bearing applications. The presence of a hydrostatic pocket (usually located in the sliding surface above the pivot area, where thin film, high oil pressure and temperature are observed) affects bearing performance under hydrodynamic operation.

In theoretical researches, there is an almost common practice not to include hydrostatic recess in thermohydrodynamic (THD) or thermoelastohydrodynamic (TEHD) analysis. This is probably due to the problems with obtaining solution for oil film geometry with pocket, the order of magnitude of the pocket depths being larger than gap thickness. In this paper, an attempt was taken to study the effect of lifting pocket on THD performance of a large tilting-pad thrust bearing of Itaipu power plant. Bearing performance was evaluated including recess shape for several cases of its depth. The results show that hydrostatic recess changes calculated bearing properties quite significantly, especially in vicinity of the pocket.

It has been shown [13] before that liquids can slip at a solid boundary, which prompted the idea that parallel-surfaces bearings can be achieved just by alternating slip and non-slip regions in the direction of fluid flow. The amount of slip at the wall depends on the surface tension at the liquid-solid interface, which in turn depends on the chemical state of the surface and its roughness. In the present study a heterogeneous surface was obtained by coating half of a circular glass disc with a coating repellant to glycerol. A rotating glass disc was placed at a known/calibrated distance and the gap was filled with glycerol. With the mobile surface moving from the direction of slip to non-slip region it can be theoretically shown that a pressure build up can be achieved. The pressure gradient in the two regions is constant, similar to that in a Rayleigh step bearing, with the maximum pressure at the separation line. The heterogeneous disc was placed on a holder supported by a load cell thus the force generated by this pressure increase can be measured accurately. Tests were carried out at different sliding speeds and gaps and the load carried was measured and subsequently compared with theoretical calculations. This allowed the slip coefficient to be evaluated.

In the study [15], based on the classical Archard adhesion wear theory, a three-dimensional finite element model was established, with the aim of simulating the failure process of self-lubricating spherical plain bearings in the swinging wear condition. The results show that the self-lubricating spherical plain bearings go through two different stages during the wear process, namely, initial wear stage and stable wear stage. Because the large contact points wear out during the initial wear stage, the maximum contact pressure decreases as the test period increases. The relatively larger wear depth region shows elliptical distribution, and the maximum distribution appears in the central contact area. The wear depth reaches $0.974 \mathrm{~mm}$ after swinging 25,000 times. PTFE fibers, which possess a good friction performance but poor abrasion resistance, abundantly exist on the friction surfaces of the fabric liner. Consequently, the friction torque during the initial wear stage is slightly smaller than the friction torque during the stable wear stage; however, the wear rate during the initial wear stage is high. The reliability and effectiveness of the finite element model are verified by experiment. The developed finite element model can be used for the analysis of the wear mechanisms of bearings and the prediction of the service life of bearings. 
I paper [15] developed a technique to assess the workability of sealed-for-life greased rolling bearings after a long-term storage. In this framework, we devised a model of equivalent transition between the conditions of natural ageing under daily and seasonally fluctuating temperature, and the conditions of accelerated thermal ageing at a constant high temperature. The tested bearings were thermally aged, and then their steady state friction and outer ring temperature were examined in a custom high-speed spindle. These results were compared to the performance of a reference new bearing tested under the same loading conditions. Our findings suggest that long-term storage can significantly degrade the performance of sealed-for-life greased rolling bearings. However, a proper running-in can substantially deter the ageing-driven degradation of the bearings.

The paper [16] presents a numerical study for nonlinear rotordynamic response with bifurcations of tilting pad journal bearings when pad-pivot friction forces are taken into account. A Stribeck friction model is employed to determine the friction coefficient for the contacts between the pads and the spherical-type pivots. The boundary/mixed/hydrodynamic friction mode is determined for each pad surface based on the instantaneous angular motion of the pads. A Jeffcott type rotor supported on 5-pad tilting pad journal bearings is used for the structural model, and finite element fluid film models are utilized to calculate the reaction forces and moments on the pads. The simulation results show that pad-pivot friction plays an important role in determining the stability of the rotor system. For the autonomous condition, the friction induces a Hopf bifurcation and generates limit cycles at high rotor spin speed $(>14 \mathrm{krpm})$, which were originally stable equilibrium states with a no friction condition. For the nonautonomous condition, the $1 \times$ synchronous response becomes subsynchronous/quasiperiodic responses in the high-speed range $(>14 \mathrm{krpm})$ with the appearances of NeimarkSacker bifurcations. It is shown that the outbreak points and corresponding response types are highly dependent on the state of disk imbalance. A comparison of the linear and nonlinear models clearly illustrates the importance of retaining nonlinear forces to determine potential deleterious vibration.

In [17] it becomes impossible to use conventional fluid film journal bearings in the hot working environments $\left(500-800^{\circ} \mathrm{C}\right)$ due to rapid thermal degradation of lubricating oils. Under this situation, powder lubricants prove beneficial in spite of high friction values associated with them in comparison to lubricating oils. Thus, reduction of friction in powder-lubricated journal bearings is an essential task for making the operation energy efficient. Hence, the objective of this paper is to explore the reduction of coefficient of friction in a powder-lubricated journal bearing employing different pocket shapes (elliptical, parabolic, rectangular, and trapezoidal) placed on bore surface. Based on the investigations reported herein, it is found that the journal bearing having rectangular pocket yields least coefficient of friction among all the cases.

Surface texturing is a technique for improving frictional and hydrodynamic performances of journal bearings because microtextures can serve as reservoirs for oil or traps for debris and may also generate hydrodynamic pressure. Over the past two decades, many researchers have experimentally demonstrated that texturing of various tribological elements can reduce friction force and wear, contributing to improvement of lubrication performance. Some numerical studies have examined the hydrodynamic lubrication conditions and reported that surface texturing affects the static characteristics of journal bearings, such as their load carrying capacity and friction torque. However, the validity of these numerical models has not been confirmed because of a lack of experimental studies. This study [18] proposes a numerical model that includes both inertial effects and energy loss at the edges of dimples on the surface of a journal bearing in order to investigate the bearing's static characteristics. Experimental verification of journal bearings is also conducted with a uniform square-dimple pattern on their full-bearing surface. The results obtained by the model agree well with those of experiment, confirming the model's validity. These results show that under the same operating conditions, textured bearings yield a higher eccentricity ratio and lower attitude angle than the conventional ones with a smooth surface. This tendency becomes more marked for high Reynolds number operating conditions and for textured bearings with a large number of dimples.

By enhancing surface properties and by reducing weight and size of machine elements, future trends in resource efficiency for machines can be fulfilled. Rolling element bearings are widely used machine elements. By improving their boundary zone properties, there is a potential to extend maintenance-free operating periods, postpone replacements or increase the lifespan of the complete system. The aim is to set favorable boundary zone properties by enhancing the residual stress state within the manufacturing process. For this, the processes hard turning and deep rolling were investigated in [19]. The influence of the initial residual stress state on fatigue life was calculated using a model based on the approach of Ioannides and Harris. The resulting residual stresses after the manufacturing process and their changes during operation in a bearing test rig are discussed and compared to those of standard bearings. The tests prove that pre-induced residual stresses increase is able to significantly delay rolling contact fatigue-related bearing failures.

The friction properties of a range of viscosity modifier-containing oils in an engine bearing have been studied in the hydrodynamic regime using a combined experimental and modelling approach [20]. The viscometric properties of these oils were previously measured and single equations derived to describe how their viscosities vary with temperature and shear rate (Marx et al. Tribol Lett 66:92, 2018). A journal bearing machine has been used to measure the friction properties of the test oils at various oil supply temperatures, while simultaneously measuring bearing temperature using an embedded thermocouple. This shows the importance of taking account of thermal response in journal bearings since the operating oil film temperature is often considerably higher than the oil supply temperature. For Newtonian oils, friction coefficient measurements made 
over a wide range of speeds, loads and oil supply temperatures collapse onto a single Stribeck curve when the viscosity used in determining the Stribeck number is based on an effective oil film temperature. Journal bearing machine measurements on VM-containing oils show that these give lower friction than a Newtonian reference oil. A thermo-hydrodynamic model incorporating shear thinning has been used to explore further the frictional properties of the VM-containing oils. These confirm the findings of the journal bearing experiments and show that two key factors determine the friction of the engine bearing; (i) the low shear rate viscosity of the oil at the effective bearing temperature and (ii) the extent to which the blend shear thins at the high shear rate present in the bearing.

Ultra-high molecular weight polyethylene (UHMWPE)/ graphene nanoplatelets (GNPs) nanocomposite coatings were developed [21] to reduce friction and wear in the absence of liquid lubrication. UHMWPE nanocomposite powders with different loadings $(0.25,1$, and $2 \mathrm{wt} . \%)$ of GNPs were prepared and electrostatic spraying technique was then used to deposit the nanocomposite powders on aluminum alloy to form a thin coating. Friction and wear tests were conducted on the coatings against a flat-end pin, made of hardened tool steel to determine the best loading of GNPs. That was further tested to investigate the effect of sliding speed and contact pressure on its tribological properties and to establish coating operating limits. Results showed that UHMWPE nanocomposite coating reinforced with $1 \mathrm{wt} \%$ GNPs showed the best tribological performance. It reduced wear rate by about $51 \%$ as compared to the pristine UHMWPE coating. The coating sustained a maximum sliding speed of $1 \mathrm{~m} / \mathrm{s}$ at a contact pressure of $4 \mathrm{MPa}$ equivalent to a pressure and velocity (PV) value of $4 \mathrm{MPa} . \mathrm{m} / \mathrm{s}$

Wind turbine drive train system failures have been the major source of down time and costly repairs. One of the main failure modes associated with gearbox failures is the formation of white etching cracks (WECs) in bearings. In this paper, low-speed intermediate shaft (LSIS) and high-speed intermediate shaft (HSIS) bearings are collected from failed gearboxes to examine microstructural alterations and evaluate damage [22]. Butterfly wing formations are detected in LSIS bearings around nonmetallic inclusions at depths of up to about $260 \mu \mathrm{m}$ from the contact surface and the measured span length ranging from 5 to $70 \mu \mathrm{m}$. Circumferential cracks oriented parallel to the contact surface are detected at depths greater than $300 \mu \mathrm{m}$. Irregular white etched cracks are revealed in HSIS bearings with random crack orientations. The crack depth is measured to be $7000 \mu \mathrm{m}$ in the cross section perpendicular to the bearing axis. The bearing characterization revealed that microstructural alterations can occur with and without the formation of cracks. Evidence found supports the existing hypotheses that (1) white etch areas precedes crack formations and (2) cracks are prerequistes for white etch formation. The microstructural alterations detected in LSIS and HSIS bearings are observed to have different crack morphology and could be initiated by different mechanisms. The results presented in this paper can be used to develop materials-based prognostic life prediction models. This can be achieved by linking WECs and butterfly wings qualitative observations to turbine real operating conditions, bearing design, and manufacturing process.

A general, CFD-based frequency response method for obtaining the dynamic coefficients of hydrodynamic bearings is presented [23]. The method is grounded in experimental parameter identification methods and is verified for an extremely long, slider bearing geometry as well as short and long journal bearing geometries. The influence of temporal inertia on the dynamic response of the bearings is discussed and quantified through the inclusion of added mass coefficients within the mechanical models of the hydrodynamic bearing films. Methods to separate the dynamic stiffness into static stiffness and added mass contributions are presented and their results compared. Harmonic perturbations are applied to the bearings at varying frequencies to determine the frequency dependence of the dynamic coefficients and to facilitate the decomposition of the dynamic stiffness into its constituents. Added mass effects are shown to be significant for the extremely long slider bearing geometry and negligible for the short and long journal bearing geometries under operating conditions motivated by those typical of marine bearings.

The paper [24] focuses on the operating behavior of journal bearings for industrial machinery application during run-ups. For this purpose, a numerical simulation code that is based on a two-dimensional extended and generalized Reynolds equation and a full three-dimensional energy equation, was advanced by a theoretical model considering the effects of mixed friction and warming of journal components during start-up. The mixed friction routine contained the elastic half-spaces model proposed by Boussinesq, which considers the influence of rough surfaces by implementing flow factors and calculates additional stiffness and dissipation in areas with solid interactions. Furthermore, a transient term was added in the energy equation to consider the thermal inertia of journal, and bearing to ensure a realistic heating during run-ups. Results of the prediction were compared to experimental data taken from a special test rig built up for validation procedures. Besides the conventional sensors for temperature, oil flow, and relative motion between shaft and stator, a contact voltage measurement was installed to determine the intensity of mixed friction. The evaluation of experimental data by Stribeck curves, based on a shaft torsion measurement, indicated a significant influence of run-up time on frictional moment. The friction coefficient of the rotor bearing system was strongly influenced by the run-up time. A short run-up time reduced the frictional coefficient in the mixed lubrication regime while the opposite behavior was observed in the hydrodynamic lubrication regime. The numerical code predicted these tendencies in good agreement with experimental data, however, only if the transient energy model was applied.

A comparative study between a conventional- and leading edge grooved (LEG) tilting pad journal bearing (TPJB) segment is performed in [25]. The developed model uses the Shear Stress Transport (SST) turbulence 
model, coupled with the energy equation and a partial differential equation for the fluid domain mesh displacement to predict the thermal flow characteristics. Instead of using an effective boundary condition to determine the inlet temperature of the LEG pad and excluding the additional LEG portion, as is common practice, the whole geometry of the LEG is modeled. Several sizes of the LEG portion is investigated and it is shown to have quite a small influence on pressure, temperature, film thickness and turbulence intensity. Moreover, the results also show that the conventional pad gives rise to higher levels of turbulence in the mid plane compared to its LEG counterpart, while the latter has a marginally higher value of turbulence when the volume average value is computed. The maximum value of turbulence is however present in the conventional model.

New stress-based life models are introduced to define "dynamic stress capacity" in rolling bearings for the first time. The generalized stress capacity equations are formulated, for both point and line contacts, in terms of distinct geometrical and materials parameters while the empirical constants are now material independent [26]. Life equations are first developed for individual rolling element to race contacts and then statistically combined to estimate lives of both races, rolling elements, and, finally, the whole bearings for both ball and roller bearings. An estimate of the empirical constant for the ball bearing equation is derived by regression analysis of available experimental data. The applicable constant for roller bearings is then derived by relating the ball and roller bearing constants to the fundamental subsurface fatigue hypothesis applicable to both point and line contacts. For AISI 52100 bearing steel at room temperature, life predictions with the new stress-based equations are in complete agreement with those currently provided by widely used load-based formulations, where the empirical constant contains the elastic properties of AISI 52100 bearing steel. In addition to these life equations based on the magnitude and depth of maximum orthogonal subsurface shear stress and the volume of material stressed, a new model that eliminates life dependence on the depth of maximum orthogonal shear stress and relates life to only the subsurface maximum shear stress and the stressed volume is presented. Though the predicted life estimates with the currently used and newly introduced life models are comparable in the contact stress range of 2 to $3 \mathrm{GPa}$, the new model provides significantly higher lives at low contact stresses.

In the article [27], a method for identification of equivalent stiffness was proposed based on a genetic algorithm by studying the stiffness characteristics of autoeliminating clearance auxiliary bearing devices (ACABDs) in static condition. Subsequently, the equivalent stiffness damping model and the Hertz contact theory were combined to establish the theoretical equations of the ACABD. Moreover, the linear equivalent model of the ACABD was established to eliminate the influence of contact of the revolute pair on mode shape and mode frequency of the rotor. In addition, simulations and experiments were carried out to verify the effectiveness of the genetic algorithm-based stiffness identification method. The results indicated that the relative errors between the equivalent stiffness in the $X$ and $Y$ directions identified by the linear equivalent model and the theoretical values were 6.22 and $7.19 \%$ respectively, demonstrating the feasibility of this identification method.

A method for forming an exact self-similar solution to the problem of hydrodynamic calculation of a radial plain bearing that operates in a steady-state friction mode in the presence of a lubricant has been constructed [28]. Based on the equation of motion for a viscous incompressible electrically conducting liquid in the case of a "thin layer," the continuity equation, and expressions for the dissipation rate of mechanical energy, an analytical relationship for the molten surface profile of fusible coating on a bearing bush taking into account the viscosity and electrical conductivity of a liquid lubricant depending on pressure is obtained. The effect of the parameters characterizing the dependence of viscosity and electrical conductivity on pressure and the effect of a parameter caused by melting the fusible coating surface of the bearing bush exerted on the bearing capacity and friction force are demonstrated.

The second version of the original Bearing Builder Finite Element Method (BBFEM) software and its application for analyzing the hydrodynamics of cylindrical sliding bearings has been briefly described [29]. The two-dimensional problem of the lubricating fluid flow in a bearing clearance taking into consideration the different types of deviations in the contact surface from a cylindrical shape has been solved by the finite element method. The bearing design that leads to the formation of several hydrodynamic friction zones (fluid wedges) has been considered. The role of the contact compliance of a shaft and a bush and the operation factors that cause the deviation from the initial cylindrical shape of a bearing, including the deformations and the misalignment of the shaft and bush is shown by citing specific examples of antifriction composites of different compositions.

Effective conditions of friction in units that ensure performance and maximum longevity have been created by flood lubrication under the conditions of elastohydrodynamic (EHD) lubrication. In connection with this, prolonging the service life of friction units by ensuring local requirements to the amount of oil in the contact area and establishing the optimum choice of lubricating material in terms of its viscosity ratings is a topical problem for rolling bearings. Thus, it is suggested to determine the parameter of the lubricating layer $(\lambda)$ values for the conditions of flood lubrication $\left(\lambda_{0}\right)$ and progressing $\left(\lambda_{o . s}\right)$ and catastrophic $\left(\lambda_{c . s}\right)$ oil starvation for a wide spectrum of lubricating materials of different viscosity, since, in oil starvation mode, the efficiency of EHD conditions is violated, the lubrication mode is disturbed, and the bearing capacity of the EHD lubricating layer is lost. 


\section{Conclusion}

The issues of creating efficient structural bearing assemblies, including through the use of new hybrid materials and structures, are considered. Much attention is paid to the problem of bearing wear and reducing the coefficient of friction. Separately considered issues of computer modeling of working conditions and design of structures. Considered modern approaches to the calculated evaluation of bearings, the solution of contact problems. This review allows scientists and engineers to do the right task setting when planning further research on bearing tribo systems.

\section{References}

1. Ali Rezaeia, WimVan Paepegema, Patrick De Baets, Wouter Ost. Adaptive finite element simulation of wear evolution in radial sliding bearings. Wear. Volume 296, Issues 1-2, 660-671, (2012).

2. Florian König, Achraf Ouald Chaib, Georg Jacobs, Christopher Sous. A multiscale-approach for wear prediction in journal bearing systems - from wearing-in towards steady-state wear. Wear, Volumes 426-427, Part B, 2019, 1203-1211

3. V. T. Oksanen, A. J. Lehtovaara, M. H. Kallio. Load capacity of lubricated bismuth bronze bimetal bearing under elliptical sliding motion. Wear, Volumes 388-389, 2017, 72-80

4. Nimeshchandra S. Patel, D. P. Vakharia, G. M. Deheri, H. C. Patel. Experimental performance analysis of ferrofluid based hydrodynamic journal bearing with different combination of materials... Wear, Volumes 376-377, Part B, 2017, 1877-1884.

5. Lidia Galda, Jaroslaw Sep, Artur Olszewski, Tomasz Zochowski. Experimental investigation into surface texture effect on journal bearings performance.Tribology International, Volume 136, 2019, 372-384

6. Surojit Poddar, N. Tandon. Detection of particle contamination in journal bearing using acoustic emission and vibration monitoring techniques. Tribology International, Volume 134, 2019, 154-164.

7. Thomas Hagemann, Christopher Zeh, Hubert Schwarze. Heat convection coefficients of a tilting-pad journal bearing with directed lubrication.Tribology International, Volume 136, 2019, 114-126.

8. Guo Xiang, Yanfeng Han, Jiaxu Wang, Jiefu Wang, Xiaokang Ni. Coupling transient mixed lubrication and wear for journal bearing modeling. Tribology International, Volume 138, 2019, 1-15.

journal bearing and thrust bearing.

9. Shaoyu Zhu, Jun Sun, Biao Li, Xiaoyong Zhao, Guixiang Zhu. Stochastic models for turbulent lubrication of bearing with rough surfaces. Tribology International, Volume 136, 2019, 224-233.

10. Shuhui Cui, Le Gu, Liqin Wang, Bo Xu, Chuanwei Zhang. Numerical analysis on the dynamic contact behavior of hydrodynamic journal bearings during start-up. Tribology International, Volume 121, 2018, 260-268.

11. T. Illner, D. Bartel, L. Deters. Determination of the transition speed in journal bearings under consideration of bearing deformation. Tribology International, Volume 82, Part A, 2015, 58-67.

12. Fillon, M., Wodtke, M. \& Wasilczuk, M. Friction (2015) 3: 266. https://doi.org/10.1007/s40544-015$0092-4$

13. Thomas, E., Pascovici, M.D. \& Glovnea, R.P. Friction (2015) 3: 287. https://doi.org/10.1007/s40544015-0098-y.

14. Xue, Y., Chen, J., Guo, S. et al. Friction (2018) 6: 297. https://doi.org/10.1007/s40544-018-0206-X.

15. Varenberg, M., Kligerman, Y., Halperin, G. et al. Friction (2018). https://doi.org/10.1007/s40544018-0255-1

16. Sitae Kim and Alan B. Palazzolo.Pad-Pivot Friction Effect on Nonlinear Response of a Rotor Supported by Tilting-Pad Journal Bearings.J. Tribol 141(9), 091701, 2019, doi: 10.1115/1.4043971

17. Faisal Rahmani, R. K. Pandey and J. K. Dutt. Performance Studies of Powder-Lubricated Journal Bearing Having Different Pocket Shapes at Cylindrical Bore Surface. J. Tribol 140(3), 031704, 2018, doi: $10.1115 / 1.4038678$

18. Hiroyuki Yamada, Hiroo Taura and Satoru Kaneko. Static Characteristics of Journal Bearings With Square Dimples . J. Tribol 139(5), 051703, 2017, doi: 10.1115/1.403577 $0855-3$

19. Pape, F., Neubauer, T., Maiß, O. et al. Tribol Lett (2017) 65: 70. https://doi.org/10.1007/s11249-017-

20. Vladescu, SC., Marx, N., Fernández, L. et al. Tribol Lett (2018) 66: 127. https://doi.org/10.1007/s11249-018-1080-4

21. Aliyu, I.K., Mohammed, A.S. \& Al-Qutub, A. Tribol Lett (2018) 66: 144. https://doi.org/10.1007/s11249-018-1096-9

22.Singh, H., Pulikollu, R.V., Hawkins, W. et al. Tribol Lett (2017) 65: 81. https://doi.org/10.1007/s11249-017-0861-5

23. Troy Snyder and Minel Braun. A CFD-Based Frequency Response Method Applied in the Determination of Dynamic Coefficients of Hydrodynamic Bearings. Part 1: Theory. Lubricants 2019, 7(3), 23; https://doi.org/10.3390/lubricants 7030023 
24. Maximilian Prölß, Hubert Schwarze, Thomas Hagemann, Philipp Zemella and Philipp Winking Theoretical and Experimental Investigations on Transient Run-Up Procedures of Journal Bearings Including Mixed Friction Conditions. Lubricants 2018, 6(4), 105; https://doi.org/10.3390/lubricants6040105

25. Philip Croné , Andreas Almqvist and Roland Larsson. Thermal Turbulent Flow in Leading Edge Grooved and Conventional Tilting Pad Journal Bearing Segments-A Comparative Study. Lubricants 2018, 6(4), 97; https://doi.org/10.3390/lubricants6040097

26. Pradeep K. Gupta \& Erwin V. Zaretsky. New Stress-Based Fatigue Life Models for Ball and Roller Bearings.cTribology Transactions, Volume 61, 2018 - Issue 2. pp. 304-324.

27 Chaowu Jin, Guochang Li, Yazhong Hu, Yuanping Xu \& Longxiang Xu.. Identification of Mechanism Stiffness of Autoeliminating Clearance for Auxiliary Bearing. Tribology Transactions, Volume 62, 2019 - Issue 2

28. Lagunova, E.O. \& Mukutadze, M.A. J. Frict. Wear (2019) 40: 88. https://doi.org/10.3103/S1068366619010112

29. Zernin, M.V., Mishin, A.V., Rybkin, N.N. et al. J. Frict. Wear (2017) 38: 242. https://doi.org/10.3103/S1068366617030163

30. Dmitrichenko, N.F., Milanenko, A.A., Hluhonets, A.A. et al. J. Frict. Wear (2017) $38: 126$. https://doi.org/10.3103/S1068366617020076.

Дыха А.В., Дытынюк В.А., Посонский С.Ф., Зеленская Л.И. Современные исследования подшипниковых трибосистем: обзор

Подшипники скольжения являются одним из важных узлов трения современных машин, обеспечивающих их длительную работу. Опоры скольжения определяют точность исполнительных движений рабочих органов машин. Создание и исследование надежных и точных подшипников скольжения является важной проблемой машиностроения. В данном обзоре представлены результаты исследований подшипников скольжения, опубликованные за последние годы в специализированных научных журналах. Рассмотрены вопросы создания эффективных конструкий подшипниковых узлов, в том числе за счет использования новых гибридных материалов и конструкций. Большое внимание уделено проблеме изнашивания подшипников и снижения коэффициента трения. Отдельно рассмотрены вопросы компьютерного моделирования условий работы и проектирования конструкций. Рассмотрены современные подходы расчетной оценки подшипников, решения контактных задач. Данный обзор позволяет ученым и инженерам делать правильные постановки задач при планировании дальнейших исследований подшипниковых трибо систем..

Ключевые слова: опорные подшипники скольжения, износ, трение, контактные задачи, лабораторные испытания. 